\title{
Analysis of epididymal proteins during sexual maturation in male albino mice
}

\author{
B. Ramanathan and G. Archunan
}

Department of Animal Science, Bharathidasan University, Tiruchirappalli, Tamilnadu, India

Received: February 27, 2001

Accepted: June 19, 2001

\begin{abstract}
Androgen dependent epididymal proteins act as antigen to produce autoantibodies and affect normal fertility. In the present study, epididymal proteins were analyzed during the time of sexual maturation and their androgen dependency was studied in male albino mice. Epididymis of 21 days (Pre-pubertal), 45 days (Pubertal), 60 days (Post-pubertal), orchidectomized (15 days after surgery) and orchidectomized with testosterone-treated (15 days after treatment) mice were dissected out and analyzed. Caput, corpus and cauda epididymidis were separated and the protein extract was prepared with $0.1 \mathrm{M}$ PBS for $10 \%$ SDS-PAGE analysis. Testosterone assay was performed in the experimental groups except the testosterone treated group. The electrophoretic analysis of proteins in caput, corpus and cauda epididymidis of orchidectomized animals showed the disappearance of several proteins as compared to the adult. However, the disappeared proteins started to reappear in testosterone treated animals.

The results suggest that removal of testis depletes the testosterone level and causes significant alteration in epididymal proteins. These proteins need further investigation for the purpose of immunocontraception by using them as antigens.
\end{abstract}

Keywords: sexual maturation, epididymal protein, androgen, orchidectomy, mouse, autoantibodies, testosterone

Contraceptive vaccine development requires the identification of physiologically active antigens specific to the reproductive system that can be inactivated by antibody binding. Most of the sperm proteins are testicular in origin (6). Using of antibodies against these sperm proteins may also affect the testis and its function (20). Epididymal proteins participate in the acquisition of sperm fertilizing ability during sperm maturation $(1,15)$. Interference with the spermatozoa during epididymal maturation

Correspondence should be addressed to:

Dr. G. Archunan

Department of Animal Science,

Bharathidasan University,

Tiruchirappalli-620 024, Tamilnadu, India

E-mail: garchu@bdu.ernet.in 
would be a suitable post testicular antifertility agent for men (2). The use of specific epididymal protein as an immunogen would be no danger of orchitis (20).

Specific sperm coating proteins include a $54 \mathrm{kDa}-\mathrm{SM} 4$ (7) which is synthesized in a discrete region of the distal caput epididymis (21) and 29-31 kDa - MEP7 (8) proteins appear on spermatozoa in more distal regions of the mouse epididymis. Hegde et al. (9) have identified the epididymal proteins 45 and $26 \mathrm{kDa}$ by using a monoclonal antibody D2G4 which is generated in female mice by hyper-immunization with human spermatozoa. Spermatozoa acquire these proteins during their passage and storage in the cauda epididymis. In rats, glycoprotein DE $(37 \mathrm{kDa})$ is specifically synthesized by the epididymis which migrates to the segment after capacitation (19). Martinez et al. (13) have reported that the immunization against DE $(37 \mathrm{kDa})$ affects fertility and that provides the use of epididymal proteins for immunocontraceptive vaccine development. Since mouse sperm proteins are having more similarity with human sperm proteins (9), mouse will be considered as a good model for immunocontraceptive approach. Hence, the present experiment was designed to identify the secretion of specific epididymal proteins during sexual maturation of the male mice and analyse their androgen dependency. It will be helpful to use the protein as an antigen for immunocontraceptive vaccine development.

\section{Materials and Methods}

Closely colony-bred male Swiss albino mice were used for the present study. All animals were housed in polypropylene cages, $40 \times 15 \times 10 \mathrm{~cm}$ size with rice husk lining the bottom as bedding material. The mice were maintained at $25{ }^{\circ} \mathrm{C}-30{ }^{\circ} \mathrm{C}$ with $12: 12 \mathrm{~h}$ light and dark cycle. The cages of mice were cleaned on every alternate day. The mice were fed with standard pellet feed (Sai feeds, Bangalore) and water at ad libitum.

The animals were divided into five groups and each group consisted of six mice. The groups were Pre-pubertal of 21 days old (I), Pubertal of 45 days old (II), Postpubertal of 60 days old (III), Orchidectomized (IV) and Orchidectomized with Testosterone-treatment (V). Orchidectomy was performed under aseptic condition, through a small vertical midline incision. The wound was closed in two layers, using absorbable suture thread for the skin. Testosterone propionate was given intraperitoneally (IP) as $0.1 \mathrm{mg} /$ day/animal for 15 days to the orchidectomized animals (from the 15th day after castration). Blood was collected through retro-orbital bleeding and the serum was separated. Serum testosterone was assayed by solid phase RIA using kits $\left(\mathrm{I}^{125}\right)$ obtained from Diagnostic Products Corporation, USA. Sensitivity of this assay was $0.04 \mathrm{ng} / \mathrm{ml}$ (approximately) for testosterone. 
Tissue extracts from caput, corpus and cauda epididymal regions were extracted by using 0.1M PBS (pH 7.2) containing $1 \mathrm{mM}$ EDTA and $2 \mathrm{mM}$ PMSF through homogenization for protein separation. Epididymal fluids and sperm were collected from caput, corpus and cauda epididymidis by mincing the tissue with sterile surgical blade in PBS. Sperm surface proteins were extracted using 1\% SDS contained $2 \mathrm{mM}$ PMSF as extraction fluid under incubation for $1 \mathrm{~h}$ at $4{ }^{\circ} \mathrm{C}$. Then the protein was extracted by vortex mixing and centrifuged at 10,000 $\mathrm{g}$ for $15 \mathrm{~min}$. The protein extract was used for $10 \%$ SDS-PAGE analysis (12) and stained by coomassie blue. Student's $t$-test was applied to assess the significance of differences for the data obtained (22).

\section{Results}

Serum testosterone showed an increase during the time of sexual maturation but in castrated animals the testosterone level was very low (Table I). There were no great differences in caput, corpus and cauda epididymal proteins of pre-pubertal mice. In prepubertal mice, 85, 52 and $56 \mathrm{kDa}$ proteins were found at caput, corpus and cauda epididymidal regions (Fig. 1). However, a $52 \mathrm{kDa}$ protein was found in the sperm extract obtained from caput, corpus and caudal regions of epididymis (Fig. 6) but it was not appeared in the caudal region of orchidectomized mice (Fig. 4).

It was specifically noticed that a $23 \mathrm{kDa}$ protein was found to be appeared in large amount in the cauda epididymal region of 45 and 60 days animals when compared with all other proteins (Figs 2 and 3), however, it was found to be disappeared in orchidectomized mice (Fig. 4). The proteins of 66, 56, 47, 37, 29, 23 and $18 \mathrm{kDa}$ molecular weight were appeared in caput, corpus and cauda epididymidis of orchidectomized with testosterone-treated mice (Fig. 5). By contrast, 23 and $18 \mathrm{kDa}$ proteins were found to be decreased in their intensity of staining which had reflected that they might be decreased in their quantity (Fig. 4).

Table I

The level of serum testosterone in different age groups and orchidectomized mice

\begin{tabular}{lc}
\hline \multicolumn{1}{c}{ Groups } & Concentration of testosterone ng/ml \\
\hline (I) Pre-pubertal (21 days) & $2.498 \pm 0.117$ \\
(II) Pubertal (45 days) & $5.463 \pm 0.123$ \\
(III) Post-pubertal (60 days) & $10.641 \pm 0.097$ \\
(IV) Orchidectomized (15 days after surgery) & $0.426 \pm 0.098$ \\
\hline
\end{tabular}

Values are Mean \pm S.E of six observations.

Significance of differences:

I vs II - P<0.05; II vs III - P<0.05; III vs I - P<0.05; III vs IV - P<0.05. 


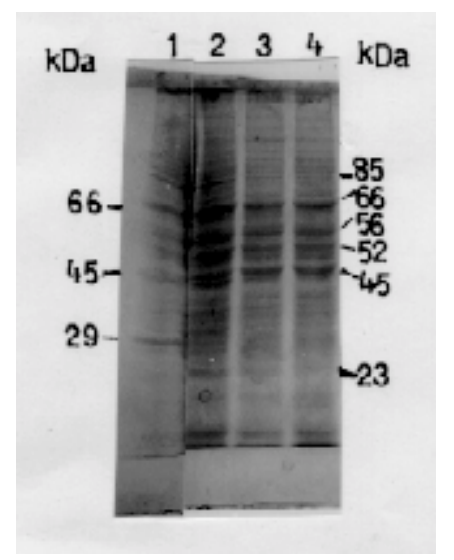

Fig. 1. SDS-PAGE analysis of protein profile differences in caput, corpus and cauda epididymidis of pre-pubertal mice (21 days old). Lane 1, molecular weight markers; lane 2, caput epididymal proteins; lane 3, corpus epididymal proteins; lane 4, cauda epididymal proteins

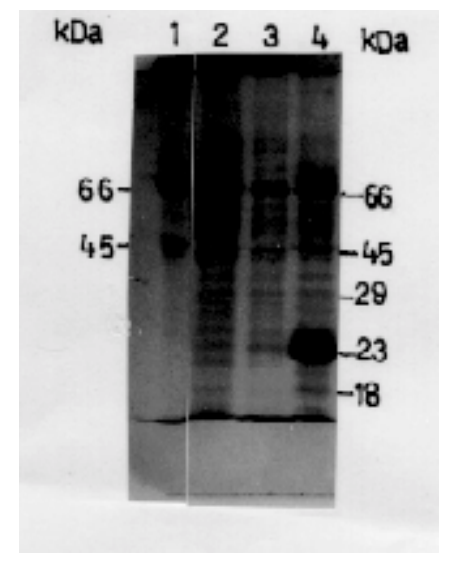

Fig. 3. SDS-PAGE analysis of protein profile differences in caput, corpus and cauda epididymidis of post-pubertal mice (60 days old). Lane 1, molecular weight markers; lane 2, caput epididymal proteins; lane 3 , corpus epididymal proteins; lane 4 , cauda epididymal proteins

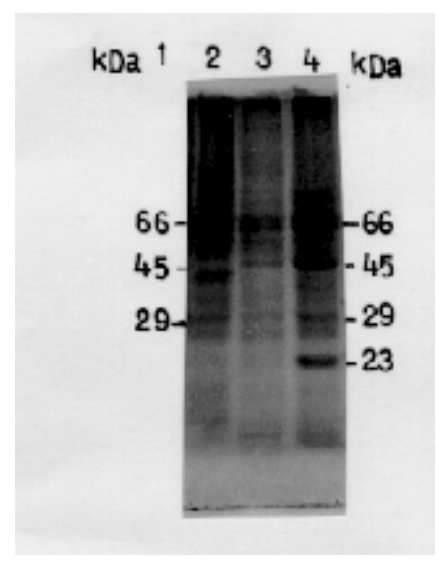

Fig. 2. SDS-PAGE analysis of protein profile differences in caput, corpus and cauda epididymidis of pubertal mice ( 45 days old). Lane 1, molecular weight markers; lane 2, caput epididymal proteins; lane 3, corpus epididymal proteins; lane 4, cauda epididymal proteins

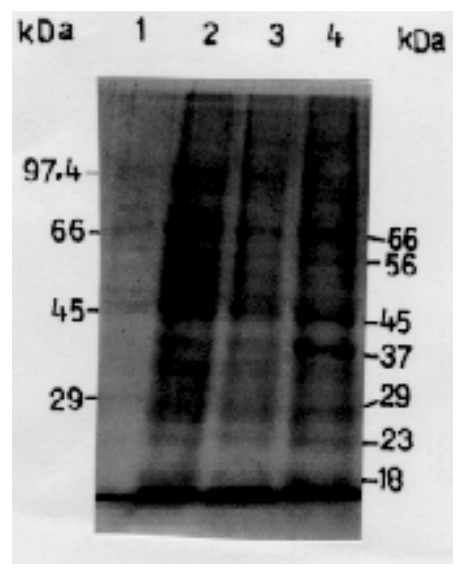

Fig. 4. SDS-PAGE analysis of protein profile differences in caput, corpus and cauda epididymidis of orchidectomized mice. Lane 1, molecular weight markers; lane 2, caput epididymal proteins; lane 3 , corpus epididymal proteins; lane 4, cauda epididymal proteins 


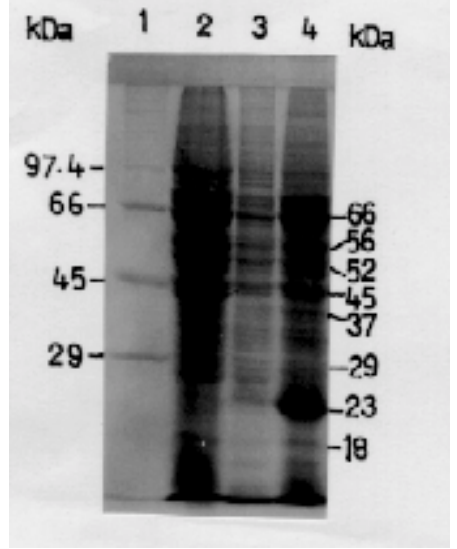

Fig. 5. SDS-PAGE analysis of protein profile differences in caput, corpus and cauda epididymidis of orchidectomized and testosterone treated mice. Lane 1, molecular weight markers; lane 2, caput epididymal proteins; lane 3, corpus epididymal proteins; lane 4, cauda epididymal proteins

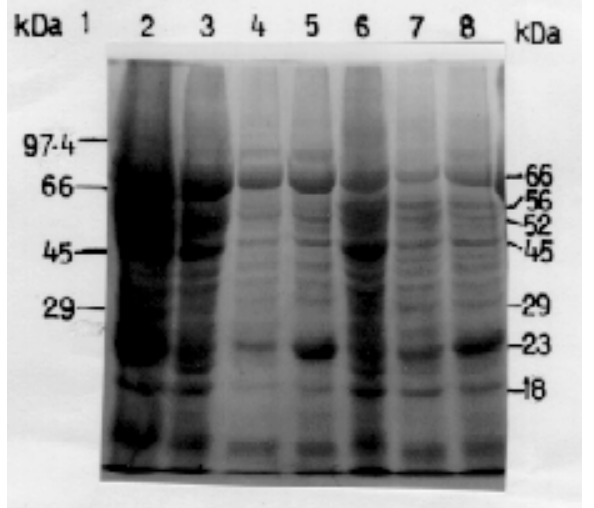

Fig. 6. Testicular fluid, epididymal fluid and sperm protein extract of 60 days old mice are electrophoretically analyzed for the presence of 29, 23 and $18 \mathrm{kDa}$ proteins. Testicular fluid shows the similar proteins that also appear in different regions of epididymal fluids and sperm extracts. Lane 1, molecular weight markers; lane 2, testicular fluid; lane 3, caput fluid; lane 4, corpus fluid; lane 5, caudal fluid; lane 6, caput sperm extract; lane 7, corpus sperm extract; lane 8 , caudal sperm extract

Epididymal fluids and sperm extracts were collected from caput, corpus and cauda epididymidal regions and they were analyzed for the presence of $23 \mathrm{kDa}$ protein. It was found that $23 \mathrm{kDa}$ protein was identified in all the lanes of epididymal fluids and sperm extracts (Fig. 6). But the $23 \mathrm{kDa}$ protein was in higher amount in the cauda epididymal fluid and cauda epididymal sperm extract. As like the presence of the $23 \mathrm{kDa}$ protein, there was another protein of $18 \mathrm{kDa}$ also identified in caput, corpus and cauda epididymal fluids of 60 days old mice (Fig. 6). It was found in sperm extracts of the three regions of the epididymis. Further, it was noted that testicular fluid of 60 days old mice also showed the presence of 9, 23 and $18 \mathrm{kDa}$ proteins (Fig. 6).

\section{Discussion}

Certain proteins of accessory sex glands are also coated the surface of spermatozoa (14). Spermatozoa go through maturation processes in the epididymis where they gain motility, attain the ability to be capacitated and undergo acrosome 
reaction (6). Androgens are required for the development and function of the male reproductive tract and accessory sex glands. Several proteins secreted by the epididymis and the accessory sex glands have been reported to be androgen dependent (11). All these proteins are important for spermatozoa to acquire fertilizing ability.

In the present study, the serum testosterone levels showed a significant increase from days 21 to 60 when the animals attained sexual maturity. Orchidectomy caused dramatic decrease in serum testosterone content after 15 days of surgery. Fernandes and Hegde (5) reported that serum testosterone levels dropped significantly after two weeks of castration. Premchandran and Hegde (16) also concluded that the plasma testosterone levels showed significant increase from 40 to 60 days. In the present study, the changes in testosterone level in sexually matured animals and orchidectomized animals are also consistent with that of the previous reports.

Mouse epididymal proteins such as MEP7 (29-kDa), MEP9 (25-kDa) and MEP10 (18-kDa) were isolated and characterized by Rankin et al. (18). Their immunohistochemical localization in epididymis was also reported. The MEP7 $(29 \mathrm{kDa})$ is heavily glycosylated protein synthesized by mice epididymal tissue from the distal caput, corpus and cauda regions (10). Similarly, the MEP9 $(25 \mathrm{kDa})$ is also reported to be a glycoprotein (17) and it is secreted by the proximal and mid-caput (18). However, the MEP10 (18 kDa) is synthesized by epididymal tissue isolated from the mid- and distal caput of mice. Interestingly, the acquiring ability of MEP7, MEP9 and MEP10 proteins by spermatozoa during their epididymal transmit has been proved by Rankin et al. (18).

It was also noticed that the $29 \mathrm{kDa}$ protein also appeared in caput, corpus and cauda epididymidis during the time of sexual maturation of mice. In mouse, an epididymal protein named MEP7 (29 kDa) characteristically similar to CRISP-1 has been identified (18). Based on the immunohistochemical localization it corresponds to that of CRISP-1. The amino acid sequence of mouse CRISP-1 indicates that it most likely represents the homologue of the previously identified rat DE/AEG (4).

Removal of testes depleted the testosterone level and caused significant changes in the protein profiles in the epididymis. It is noteworthy that as to the present investigation several proteins $(29,23$ and $18 \mathrm{kDa})$ start to be synthesized in the epididymis during the time of sexual maturation which have been depleted in orchidectomized animals and again start to synthesize those proteins in testosteronereplaced animals. From these findings, it may be concluded that for normal synthesis and secretion these proteins are androgen-dependent. Testicular origin proteins are transmitted through the epididymis which may be utilized for sperm maturation process. Cuasnicu and Rochwerger (3) reported that epididymal proteins helped to improve sperm motility and fertilizing ability. Reports indicate that epididymal proteins 29, 25 and $18 \mathrm{kDa}$ are secreted in the epididymis and bound on sperm surface (18). 
In the present study, these proteins are also found in sperm extracts which suggest that they may be bound on the sperm surface during the time of sperm transition through the epididymis. Since these proteins are also present in the testicular fluid, it is reasonable to presume that these proteins are synthesized in the testis along with sperm production and they are later transmitted through the epididymis for maintaining sperm viability and functional ability. It is possible to conclude that these proteins may be synthesized both in testis and epididymis. Some more peaces of evidence is required to support this concept. Investigations are going on to understand whether the proteins are specific to testis or epididymis or both testis and epididymis. Further, the crossreactivity of the antibodies produced against these proteins $(29,23$ and $18 \mathrm{kDa}$ ) may be analyzed with other mammalian sperm proteins and the sequential homology of these proteins will provide the evolutionary significance. These approaches may throw some new lights for using the protein as the candidate for immunocontraception.

\section{Acknowledgement}

Senior Research Fellowship provided to B.R. from Council of Scientific and Industrial Research, New Delhi, India is gratefully acknowledged.

\section{REFERENCES}

1. Bedford, J. M.: Maturation, transport and fate of spermatozoa in the epididymis. In: Handbook of Physiology, Vol. V. Hamilton, D. W., Greep, R. O. (eds). American Physiological Society, Washington. pp. 303-317 (1975).

2. Cooper, T. G., Waites, G. M. H., Nieschlag, E.: The epididymis and male fertility: A symposium report. Int. J. Androl. 9, 81-90 (1986).

3. Cuasnicu, P. S., Rochwerger, L.: Redistribution of a sperm epididymal protein after capacitation and its potential participation in sperm-egg fusion. In: Comparative spermatology, 20 years after, Vol. 75. (ed. Bachetti, B.), Raven Press, New York, pp. 555-560 (1991).

4. Eberspaecher, U., Roosterman, D., Kratzschmar, J., Haendler, B., Hhabenicht, U. F., Becker, A., Quensel, C., Petri, T., Schleuning, W. D., Donner, P.: Mouse androgen-dependent epididymal Glycoprotein CRISP-1 (De/AEG): Isolation, biochemical characterization and expression in recombinant form. Mol. Reprod. Develop. 42, 157-172 (1995).

5. Fernandes, J. E., Hegde, U. C.: Immunological characterization and antifertility effect of an androgen independent antigen of spermatozoa identified by a monoclonal antibody (D7G3). Indian J. Biochem. Biophys. 34, 274-287 (1997).

6. Feuchter, F. A., Vernon, R. B., Eddy, E. M.: Analysis of sperm surface with monoclonal antibodies: topographically restricted antigens appearing in the epididymis. Biol. Reprod. 24, 1099-1110 (1981).

7. Feuchter, F. A., Tabet, A. J., Green, M. F.: Maturation antigen of the mouse sperm flagellum. I. Analysis of its secretion, association with sperm and function. American J. Anat. 181, 67-76 (1988). 
8. Flickenger, C. J., Herr, J. C., Klotz, K. L.: Immunocytochemical localization of specific rat epididymal fluid from the cauda in the epithelium of the mouse epididymis. Cell and Tissue Research 251, 603-610 (1988).

9. Hegde, U. C., Khole, V., Premchandran, S.: Immunocytochemical localization and characterization of proteins from mouse canda epididymis using human sperm specific monoclonal antibody. Hum. Reprod. 6, 259-262 (1991).

10. Holland, M. K., Orgebin-Crist, M. C.: Characterization and hormonal regulation of sperm synthesis by the murine epididymis. Biol. Reprod. 38, 487-496 (1988).

11. Jimenez, C., Ghyselinck, N. B., Depeiges, A., Dufaure, J. P.: Immunological localization and association with spermatozoa of androgen regulated proteins of Mr 24000 secreted by the mouse epididymis. Biol. Cell 68, 171-174 (1990).

12. Laemmli, U. K.: Cleavage of structural proteins during the assembly of the head of bacteriophage T4. Nature 227, 680-685 (1970).

13. Martinez, S. P., Conesa, D., Cuasnicu, P. S.: Potential contraceptive use of epididymal proteins: evidence for the participation of specific antibodies against rat epididymal protein DE in male and female fertility inhibition. J. Reprod. Immunol. 29, 31-45 (1995).

14. Moore, H. D. M.: Localization of specific glycoproteins secreted by the rabbit and hamster epididymis. Biol. Reprod. 22, 705-718 (1980).

15. Orgebin-Crist, M. C., Danzo, B. J., Davies, J.: Endocrine control of the development and maintenance of sperm fertilizing ability in the epididymis. In: Handbook of Physiology, Vol. V. (Hamilton, D. W., Greep, R. O. eds.) American Physiol. Soc., Washington. pp. 319-338 (1975).

16. Premchandran, S., Hegde, U. C.: Ontogeny of mouse caudal proteins identified by a monoclonal antibody. Hum. Reprod. 6, 589-592 (1991).

17. Rankin, T. L., Holland, M. K., Orgebin-Crist, M. C.: Lectin binding characteristics of mouse epididymal fluid and sperm extracts. Gamete Res. 24, 439-451 (1989).

18. Rankin, T. L., Tsuruta, K. J., Holland, M. K., Griswold, M. D., Orgebin-Crist, M. C.: Isolation, Immunolocalization, and sperm-association of three proteins of 18, 25 and 29 kilodaltons secreted by the mouse epididymis. Biol. Reprod. 46, 747-766 (1992).

19. Rochwerger, L., Cuasnicu, P. S.: Redistribution of rat sperm epididymal glycoprotein after in vitro and in vivo capacitation. Mol. Reprod. Develop. 31, 34-41 (1992).

20. Talwar, G. P., Singh, O., Pal, R., Chatterjee, N., Suri, A. K., Shaha, C.: Vaccines for control of fertility. Indian J. Exp. Biol. 30, 947-950 (1992).

21. Vernon, R. B., Muller, C. H., Herr, J. C., Feuchter, F. A., Eddy, E. M.: Epididymal secretion of a mouse sperm surface component recognized by a monoclonal antibody. Biol. Reprod. 26, 523-535 (1982).

22. Zar, J. H. (1984): Biostatistical analysis. Printice Hall, Englewood Cliffs, New Jersey p. 185. 